\title{
ВЛИЯНИЕ ПИРИТА НА ВЫХОД И СОСТАВ ПРОДУКТОВ ПОЛУКОКСОВАНИЯ ГОРЮЧИХ СЛАНЦЕВ.
}

\section{2. СЛАНЕЦ-КУКЕРСИТ}

\section{(Представил О. Киррет)}

В опытах использовали смеси флотационного концентрата керогена кукерсита $\left(A^{d}=13,4 \%\right)$ и пиритного концентрата, характеристика которого приведена в [']; там же описана методика эксперимента.

Из данных о выходе продуктов полукоксования (табл. 1, рис. 1) следует, что, как и в случае диктионемового сланца ['], пирит весьма существенно подавляет образование смолы из кукерсита: при уменьшении содержания условной органической массы в смеси от 85 до $19 \%$ выход смолы полукоксования в расчете на кероген снижается от 58 до $17 \%$. Кривые зависимости выхода твердого остатка разложения и пирогенетической воды от содержания пирита в смеси имеют вид, подобный наблюдавшемуся для диктионемового сланца; причина наличия минимумов в средней части этих кривых обсуждалась ранее [']. Заметного возрастания выхода газообразных продуктов деструкции по мере увеличения содержания пирита в модельной смеси, отмеченного для диктионемового сланца, в данном случае, однако, не наблюдается.

Характеристика исходных модельных смесей и выход из них продуктов полукоксования, \%

\begin{tabular}{l|l|l|l|l|l|l|l|l}
\hline & \multicolumn{8}{|c}{ Номер опыта } \\
\cline { 2 - 5 } Показатель & 1 & 2 & 3 & 4 & 5 & 6 & 7 & 8 \\
\hline
\end{tabular}

Исходные смесн:

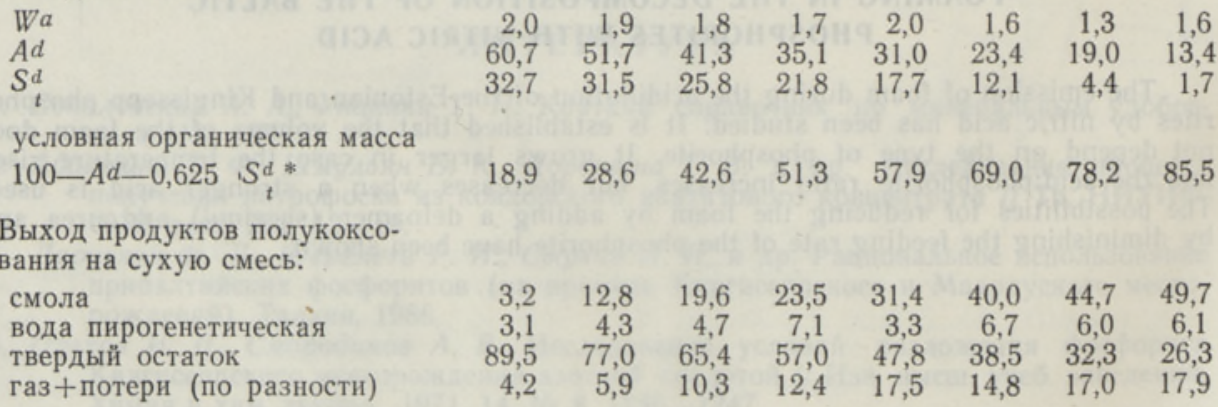

* Содержание углекислоты карбонатов, составлявшее до 0,2\% (в опыте 8), не учитывалось. Условную органическую массу находили, как и в ['], по упрощенной формуле Крыма. 


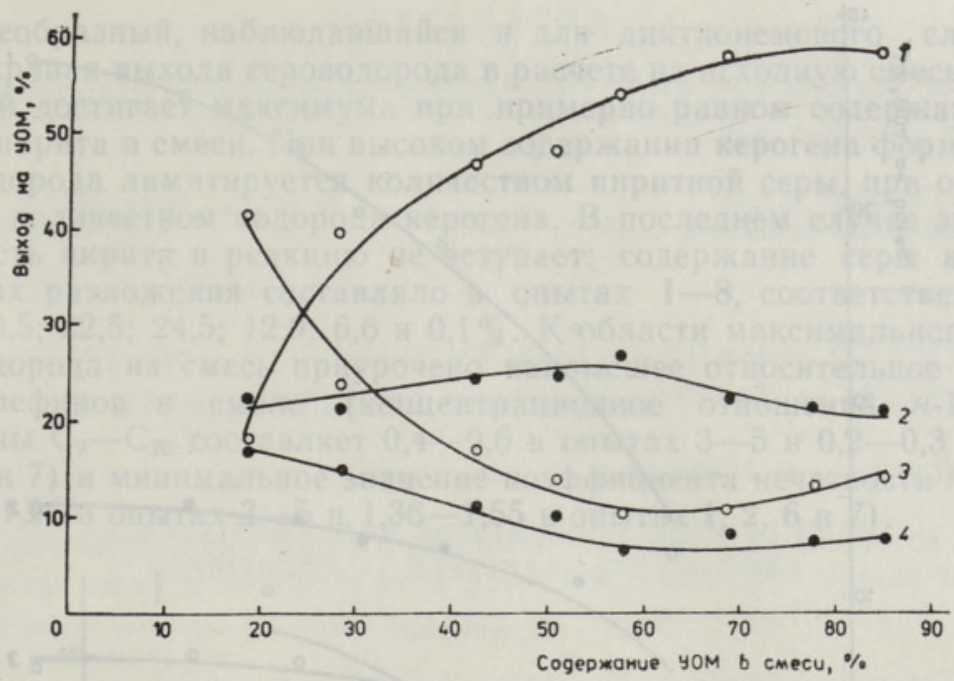

Рис. 1. Зависимость выхода продуктов полукоксования на условную органическую массу (УОМ, здесь и на рис. 2,3 ) от ее содержания в смеси с пиритом: 1 - смола, 2 - газообразные продукты, 3 - твердый остаток разложения, 4 - пирогенетическая вода.

Характерно изменение состава смолы полукоксования с ростом концентрации пирита в исходной смеси (табл. 2, рис. 2): как и другие минеральные компоненты сланцев, пирит обусловливает наиболее быстрое уменьшение выхода гетероатомных соединений смолы в расчете на органическое вещество (OB), за ними следуют ароматические и неароматические углеводороды, т. е. степень его влияния на выход отдельных групповых компонентов смолы связана с их полярностью.

С возрастанием содержания пирита в модельной смеси плотность смолы возрастает (табл. 2), что наблюдалось и для диктионемового сланца. Әто проявляется также в соотношениях концентраций отдельных компонентов смолы. Так, например, состав н-алкилпроизводных резорцина, характерной группы соединений в смоле из кукерсита, явно утяжеляется: концентрационное отношение 5-метилрезорцин: 5-н-амилрезорцин снижается от 1,5 в опыте 7 до 1,2 в опыте 1.

Таблица 2

Характеристика смол полукоксования

\begin{tabular}{|c|c|c|c|c|c|c|c|c|}
\hline \multirow{2}{*}{ Показатель } & \multicolumn{8}{|c|}{ Номер опыта } \\
\hline & 1 & 2 & 3 & 4 & 5 & 6 & 7 & 8 \\
\hline Плотность $Q_{4}^{20}$ & 0,991 & 0,988 & 0,98 & 0,978 & $3 \quad 0,975$ & 0,967 & $7 \quad 0,960$ & 0,943 \\
\hline $\begin{array}{l}\text { Элементный состав, \%: } \\
\mathrm{C} \\
\mathrm{H} \\
\mathrm{S} \\
\mathrm{O}+\mathrm{N} \text { (по разности) * }\end{array}$ & $\begin{array}{r}79,5 \\
9,6 \\
4,0 \\
6,9\end{array}$ & $\begin{array}{r}82,9 \\
10,2 \\
1,8 \\
5,1\end{array}$ & $\begin{array}{r}83,0 \\
10,0 \\
2,4 \\
4,6\end{array}$ & $\begin{array}{r}83,2 \\
9,7 \\
2,3 \\
4,8\end{array}$ & $\begin{array}{r}83,0 \\
9,5 \\
2,7 \\
4,8\end{array}$ & $\begin{array}{r}83,2 \\
10,2 \\
1,4 \\
5,2\end{array}$ & $\begin{array}{r}84,2 \\
10,6 \\
1,0 \\
4,2\end{array}$ & $\begin{array}{r}84,4 \\
10,7 \\
1,0 \\
3,9\end{array}$ \\
\hline $\begin{array}{l}\text { Групповой химический } \\
\text { состав, \%: }\end{array}$ & & & & & & & & \\
\hline $\begin{array}{l}\text { углеводороды } \\
\text { неароматические } \\
\text { ароматические } \\
\text { гетероатомные соединения } \\
\text { нейтральные } \\
\text { кислотные }\end{array}$ & $\begin{array}{r}32,0 \\
7,2 \\
24,8 \\
68,0 \\
54,0 \\
14,0\end{array}$ & $\begin{array}{r}35,7 \\
7,2 \\
28,5 \\
64,3 \\
50,0 \\
14,3\end{array}$ & $\begin{array}{l}38,7 \\
11,1 \\
27,6 \\
61,3 \\
43,0 \\
18,3\end{array}$ & $\begin{array}{l}38,5 \\
11,3 \\
27,2 \\
61,5 \\
40,5 \\
21,0\end{array}$ & $\begin{array}{l}38,1 \\
12,3 \\
25,8 \\
61,9 \\
47,2 \\
14,7\end{array}$ & $\begin{array}{l}37,7 \\
12,0 \\
25,7 \\
62,3 \\
44,4 \\
17,9\end{array}$ & $\begin{array}{c}44,4 \\
9,2 \\
35,2 \\
55,6 \\
38,1 \\
17,5\end{array}$ & $\begin{array}{l}36,2 \\
11,0 \\
25,2 \\
63,8 \\
49,1 \\
14,7\end{array}$ \\
\hline
\end{tabular}




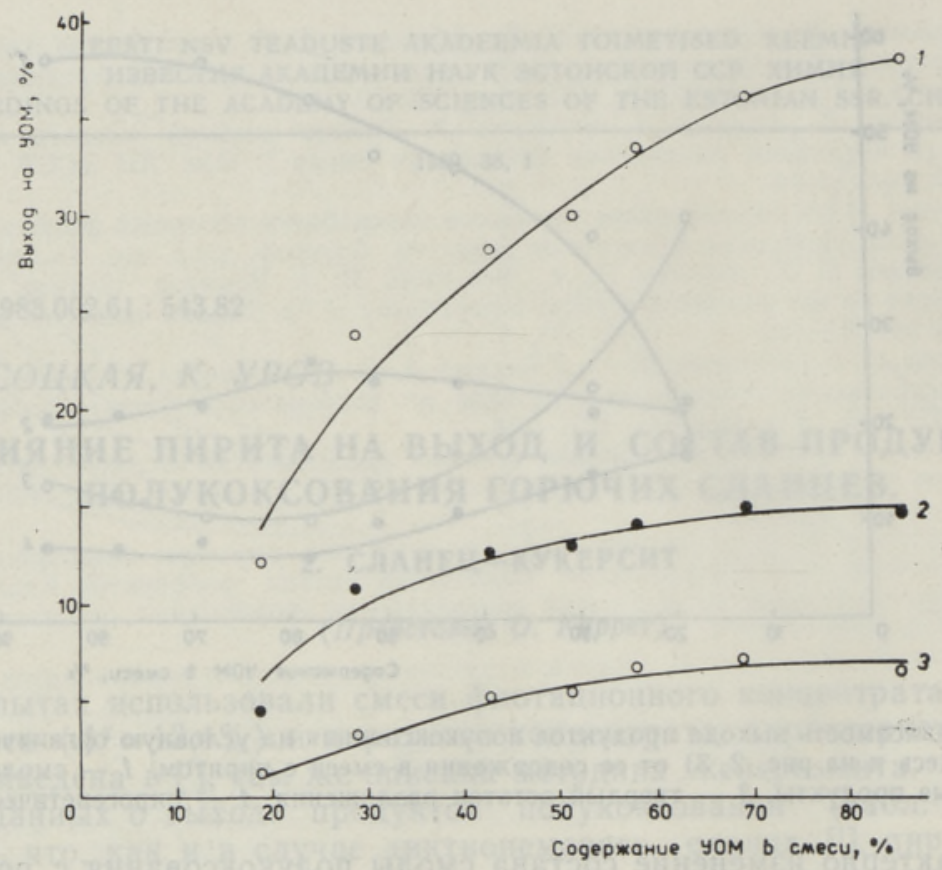

Рнс. 2. Зависимость выхода групповых компонентов смолы полукоксования на УОМ от ее содержания в смеси с пиритом: 1 - гетероатомные соединения, 2 - ароматические углеводороды, 3 - неароматические углеводороды.

Газообразные продукты полукоксования отличаются, как и в случае диктионемового сланца, высоким содержанием сероводорода (табл. 3), выход которого в расчете на ОВ достигает $16,8 \%$. Учитывая, что исходный концентрат керогена содержит 1,7\% серы, из которой может образоваться до $2,1 \%$ сероводорода на кероген, ясно, что подавляющая часть сероводорода образуется за счет пиритной серы. Расход необходимого для формирования смолы водорода на образование сероводорода приводит к уменьшению выхода смолы, а ее дегидрирование и, возможно, укрупнение (полимеризация) молекул образующихся при этом непредельных соединений - к указанному выше возрастанию плотности.

Таблица 3

Состав газообразных продуктов полукоксования,

$\%$ по объему (в пересчете на безвоздушный газ)

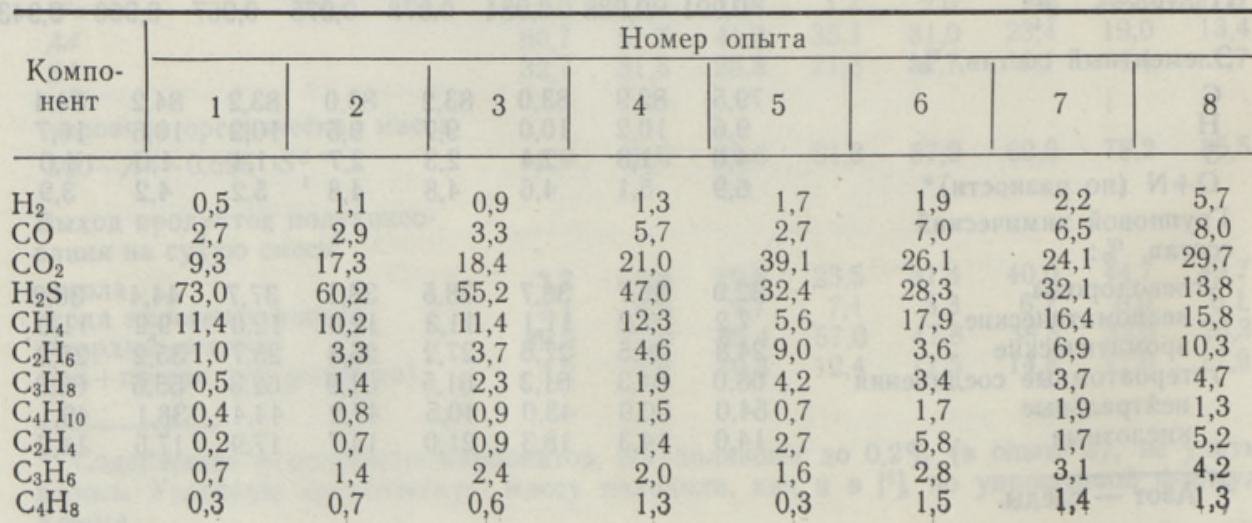


Своеобразный, наблюдавшийся и для диктионемового сланца вид имеет кривая выхода сероводорода в расчете на исходную смесь (рис. 3), который достигает максимума при примерно равном содержании керогена и пирита в смеси. При высоком содержании керогена формирование сероводорода лимитируется количеством пиритной серы, при очень низком - количеством водорода керогена. В последнем случае значительная часть пирита в реакцию не вступает: содержание серы в твердых остатках разложения составляло в опытах $1-8$, соответственно, 34,2 ; 33,$5 ; 30,5 ; 22,5 ; 24,5 ; 12,9 ; 6,6$ и $0,1 \%$. К области максимального выхода сероводорода на смесь приурочено наивысшее относительное содержание олефинов в смоле (концентрационное отношение $\boldsymbol{H}$-1-алкены: $\boldsymbol{H}$-алканы $\mathrm{C}_{9}-\mathrm{C}_{20}$ составляет $0,4-0,6$ в опытах $3-5$ и $0,2-0,3$ в опытах $1,2,6$ и 7) и минимальное значение коэффициента нечетности $\boldsymbol{H}$-алканов $(1,12-1,22$ в опытах $3-5$ и $1,36-1,55$ в опытах $1,2,6$ и 7$)$.

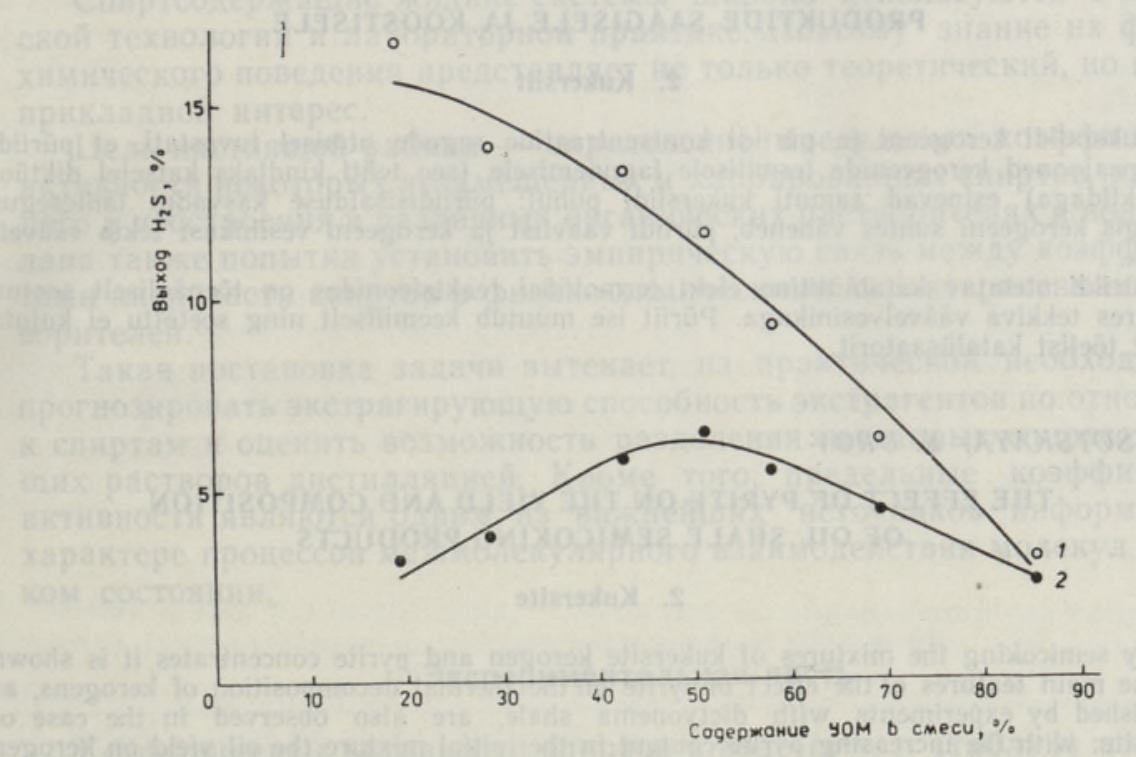

Рис. 3. Зависимость выхода сероводорода от содержания УОМ в исходной смеси: 1 - на УОМ, 2 - на исходную смесь.

В отличие от диктионемового сланца для смесей керогена кукерсита и пирита при высоком содержании последнего не наблюдалось уменьшения выхода сероводорода в расчете на кероген (из-за вероятного дефицита доноров водорода). Можно полагать, что вследствие относительно высокого содержания керогена $(19 \%)$ в даже наиболее бедной смеси и более высокого содержания в нем водорода по сравнению с ОВ диктионемового сланца состояние, характеризующееся недостатком в системе соединений с подвижными атомами водорода, не было достигнуто.

Таким образом, характер воздействия пирита на термическую деструкцию керогенов, установленный на примере диктионемового сланца, в основных чертах повторился в опытах с кукерситом: с возрастанием содержания пирита в исходном сырье для полукоксования выход смолы иа ОВ уменьшается, из пиритной серы и водорода керогена образуется цополнительное количество сероводорода.

Весьма правдоподобно, что каталитический эффект пирита в процессах термолиза ['] на самом деле обусловлен образующимся из него сероводородом, Поскольку пирит при этом подвергается химическим превращениям, типичным катализатором он не является, 
1. Высоцкая B., Уров $K$. Влияние пирита на выход и состав продуктов полукоксования горючих сланцев. 1. Диктионемовый сланец ЭССР // Изв. АН ЭССР. Хим., 1988, 37, № 4, 241-247.

\section{Ннститут химии \\ Академии наук Эстонской ССР}

Поступила в редакцию 12/IV 1988

V. VOSSOTSKAJA, K. UROV

\section{PURIIDI MÕJU PÕLEVKIVIDE POOLKOKSISTAMISE PRODUKTIDE SAAGISELE JA KOOSTISELE}

\section{Kukersiit}

Kukersiidi kerogeeni ja püriidi kontsentraatide segude utmisel tuvastati, et püriidi môju peajooned kerogeenide termilisele lagunemisele (see tehti kindlaks katsetel diktüoneemakildaga) esinevad samuti kukersiidi puhul: püriidisisalduse kasvades lähtesegus õlisaagis kerogeeni suhtes väheneb, püriidi väävlist ja kerogeeni vesinikust tekib väävelvesinik.

Püriidi oletatav katalüütiline efekt termolüüsi reaktsioonides on tõenäoliselt seotud seejuures tekkiva väävelvesinikuga. Püriit ise muutub keemiliselt ning seetôttu ei kujuta endast tõelist katalüsaatorit.

V. VYSOTSKAYA, K. UROV

\section{THE EFFECT OF PYRITE ON THE YIELD AND COMPOSITION OF OIL SHALE SEMICOKING PRODUCTS}

\section{Kukersite}

By semicoking the mixtures of kukersite kerogen and pyrite concentrates it is shown that the main features of the effect of pyrite on the thermal decomposition of kerogens, as established by experiments with dictyonema shale, are also observed in the case of kukersite: with the increasing pyrite content in the initial mixture the oil yield on kerogen decreases, the sulfur of pyrite and hydrogen of kerogen yielding hydrogen sulfide.

The presumable catalytic effect of pyrite in the thermolysis reactions is probably bound with the formation of hydrogen sulfide. Pyrite itself undergoes chemical changes and therefore cannot be regarded as a typical catalyst. 